a. Unidad Emergencias, Hospital "Prof. Dr. Juan P. Garrahan" Buenos Aires, Argentina. Sociedad Latinoamericana de Emergencias Pediátricas (SLEPE)

b. Unidad Emergencias, Hospital "Prof Dr Juan P. Gar Pror. Di. Juan P. Gar Buenos Aires, Argentina. Sociedad Latinoamericana de Emergencias Pediátricas (SLEPE) c. Instituto de Ciencias e Innovación en Medicina, Universidad del Desarrollo y Hospital El Carmen de Maipú, , Santiago, Chile. Red Colaborativa (LARediátrica de Latino

(LARed Network).
d. Unidad de Cuidados Intensivos Pediátricos, Hospital General de Medellín. Docente de cátedra, Universidad de Antioquía, Colombia. Red Colaborativa Pediátrica de Latinoamérica (LARed Network).

(LARed Network).
Cuidados Intensivos Pediátrico Especializados (CIPe), Casa de Galicia, Montevideo, Uruguay. Red Colaborativa Pediátrica de Latinoamérica (LARed Network).

f. Universidad Nacional de

Colombia y Fundación

Universitaria de Ciencias de

la Salud, Bogotá, Colombia. Red Colaborativa Pediátrica de Latinoamérica (LARed Network).

g. Departamento de Pediatría y

Cuidados Críticos, Universidad

de la Sabana. Fundación

Cardioinfantil, Instituto de

Cardiología, Bogotá, Colombia. Red Colaborativa Pediátrica de Latinoamérica (LARed Network)

h. Unidad de Cuidados Intensivos Pediátricos, Complejo Médico Policial "Churruca Visca",

Buenos Aires, Argentina. Comité de Shock, Sociedad Argentina de de Shock, Socieda.

Terapia Intensiva.
Servicio de Cuidados

Intensivos, Hospital Regional de Reconquista, Santa Fe, Argentina. Red Colaborativa Pediátrica de Latinoamérica (LARed Network). Universide Cática de Sanork).

Pediátricos, Hospital Doctor
Pnidad de Cuidados Intensivos Pediátricos, Hospital Doctor Argentina. Comité de Shock, Sociedad Argentina de Terapia Intensiva.

k. Facultad de Medicina,

Universidad Nacional del

Nordeste, Corrientes, Argentina. Red Colaborativa Pediátrica de

Latinoamérica (LARed Network).

Correspondencia:

Dr. Guillermo Kohn-

Loncarica:

gkohnloncarica@gmail.com

Financiamiento: Ninguno.

Conflicto de intereses:

Ninguno que declarar.

Recibido: 15-7-2020

Aceptado: 22-7-2020

\title{
Recomendaciones para el manejo inicial del síndrome inflamatorio multisistémico relacionado temporalmente con COVID-19, en niños y adolescentes
}

\author{
Recommendations for the initial management of multisystem \\ inflammatory syndrome temporally related to COVID-19, in \\ children and adolescents
}

\author{
Dr. Guillermo Kohn-Loncarica ${ }^{a}$, Dra. Ana Fustiñana ${ }^{b}$, Dr. Franco Díaz-Rubioc, \\ Dr. Juan C. Jaramillo-Bustamanted, Dr. Sebastián González-Dambrauskase, \\ Dr. Pablo Vásquez-Hoyosf, Dr. Jaime Fernández-Sarmientog, Dr. Gustavo González ${ }^{h}$, \\ Dr. Alejandro Mansuri, Dr. Javier Poncej y Dr. Roberto Jabornisky ${ }^{k}$
}

\section{RESUMEN}

El síndrome inflamatorio multisistémico en niños y adolescentes temporalmente relacionado con COVID-19 es una presentación clínica de la infección por SARS-CoV-2. Comparte algunas características con la enfermedad de Kawasaki, el shock tóxico, la sepsis, el síndrome de activación macrofágica y la miocarditis. Son escasas las publicaciones que abordan su manejo inicial, que tiene semejanzas con el propuesto para el shock séptico. Esta revisión analiza dicho abordaje basado en las características propias del síndrome inflamatorio multisistémico relacionado con COVID-19, de acuerdo con el paradigma de construcción de una "guía de práctica institucional", y sugiere estrategias de aproximación terapéutica, que incluyen detección temprana, estabilización, referencia, tratamiento específico y análisis de procesos.

Palabras clave: paquetes de atención al paciente, sindrome inflamatorio multisistémico, COVID-19, sepsis, SARS-CoV-2.

http: / / dx.doi.org/10.5546/ aap.2020.e514

Texto completo en inglés:

http: / / dx.doi.org/10.5546/ aap.2020.eng.e514

Cómo citar: Kohn-Loncarica G, Fustiñana A Díaz-Rubio F, Jaramillo-Bustamante JC, et al. Recomendaciones para el manejo inicial del síndrome inflamatorio multisistémico relacionado temporalmente con COVID-19, en niños y adolescentes. Arch Argent Pediatr 2020;118(6):e514-e526.

\section{INTRODUCCIÓN}

Coronavirus Infectious Disease 19 (COVID-19) fue declarada pandemia en 2020. ${ }^{1}$ Hasta el momento, ha tenido un bajo impacto en pediatría tanto en frecuencia como en gravedad, y se han reportado diversas presentaciones clínicas. ${ }^{2-9}$

Desde el mes de mayo, se han descrito casos clínicos en niños europeos previamente sanos, y se ha informado la aparición de un fenómeno asociado a COVID-19 caracterizado por una respuesta hiperinflamatoria. ${ }^{10-14}$ Este, denominado síndrome inflamatorio multisistémico temporalmente asociado a COVID-19 (SIM-C), comparte características clínicas con la enfermedad de Kawasaki (EK), con el síndrome de shock tóxico (SST), con la sepsis, con el síndrome de activación macrofágica, con la linfohistiocitosis hemofagocítica y también podría presentarse asociado a shock cardiogénico por miocarditis. ${ }^{15-22}$

Actualmente, el SIM-C es una enfermedad infrecuente, solapada con otras entidades, que requiere una alta sospecha clínica para identificarlo oportunamente. ${ }^{10-22}$ Como la sepsis, presenta una respuesta inmune inadecuada a una infección que genera fallas en distintos sistemas y representa una importante amenaza a la vida. ${ }^{23}$ En ambas situaciones, es esencial un alto nivel de suspicacia 
diagnóstica y su manejo podría requerir intervenciones de sostén vital avanzado rápidas y oportunas en el contexto adecuado. El pronóstico actual del SIM-C es bueno, con reportes de baja mortalidad, aunque su reconocimiento tardío podría empeorar los resultados. ${ }^{10-22}$

Aunque la Campaña para Sobrevivir a la Sepsis (Surviving Sepsis Campaign-SSC-), recientemente, ha actualizado las guías de práctica clínica (GPC) para el soporte hemodinámico del shock séptico (ShS) en pediatría, escasos artículos abordan el manejo inicial del SIM-C.,24-27 Gobiernos como el de la Argentina lo han incorporado como criterio diagnóstico de COVID-19, lo que sugiere la necesidad de proporcionar estrategias de atención a los proveedores de atención médica. ${ }^{5,28}$

En 2019, en Archivos Argentinos de Pediatría, se publicaron las actualizaciones del manejo inicial del ShS pediátrico y se propusieron "paquetes de medidas" para su abordaje. ${ }^{29,30}$ Se destaca la necesidad de construir guías de práctica institucionales (GPI) elaboradas por todo el equipo de salud (emergencias, internación, cuidados críticos, farmacia, laboratorio, hemoterapia, profesionales del nivel prehospitalario y de atención primaria de la salud, entre otros) para coordinar un diagnóstico y tratamiento sensible al tiempo, en la que son protagonistas el contexto y el trabajo conjunto. ${ }^{29}$

Nuestro objetivo es, con la información disponible hasta el momento, proponer recomendaciones para la construcción de paquetes de medidas institucionales (detección temprana, tratamiento, estabilización, referencia y análisis de los procesos) para el manejo inicial del SIM-C, destinadas a mejorar la calidad de atención de los niños con esta enfermedad.

\section{PAQUETES DE MEDIDAS}

Los "paquetes de medidas de cuidados del paciente" (patient care bundles) son acciones diagnóstico/terapéuticas para abordar y controlar mejor los procesos médicos. ${ }^{31}$ Contienen prácticas basadas en diferentes niveles de evidencia, relacionadas con un proceso asistencial, que, al ser desarrolladas colectivamente, logran un resultado sinérgico que mejora la atención (Figura 1). Se propusieron cinco paquetes: detección temprana, reanimación inmediata y sensible en el tiempo, estabilización, referencia

FIGURA 1. Paquetes de medidas en el síndrome inflamatorio multisistémico temporalmente asociado a COVID-19 y sus elementos para reconocimiento, reanimación o resucitación, estabilización, referencia y medición de los procesos (tomado de Kohn Loncarica y cols. y modificado por los autores $)^{30}$

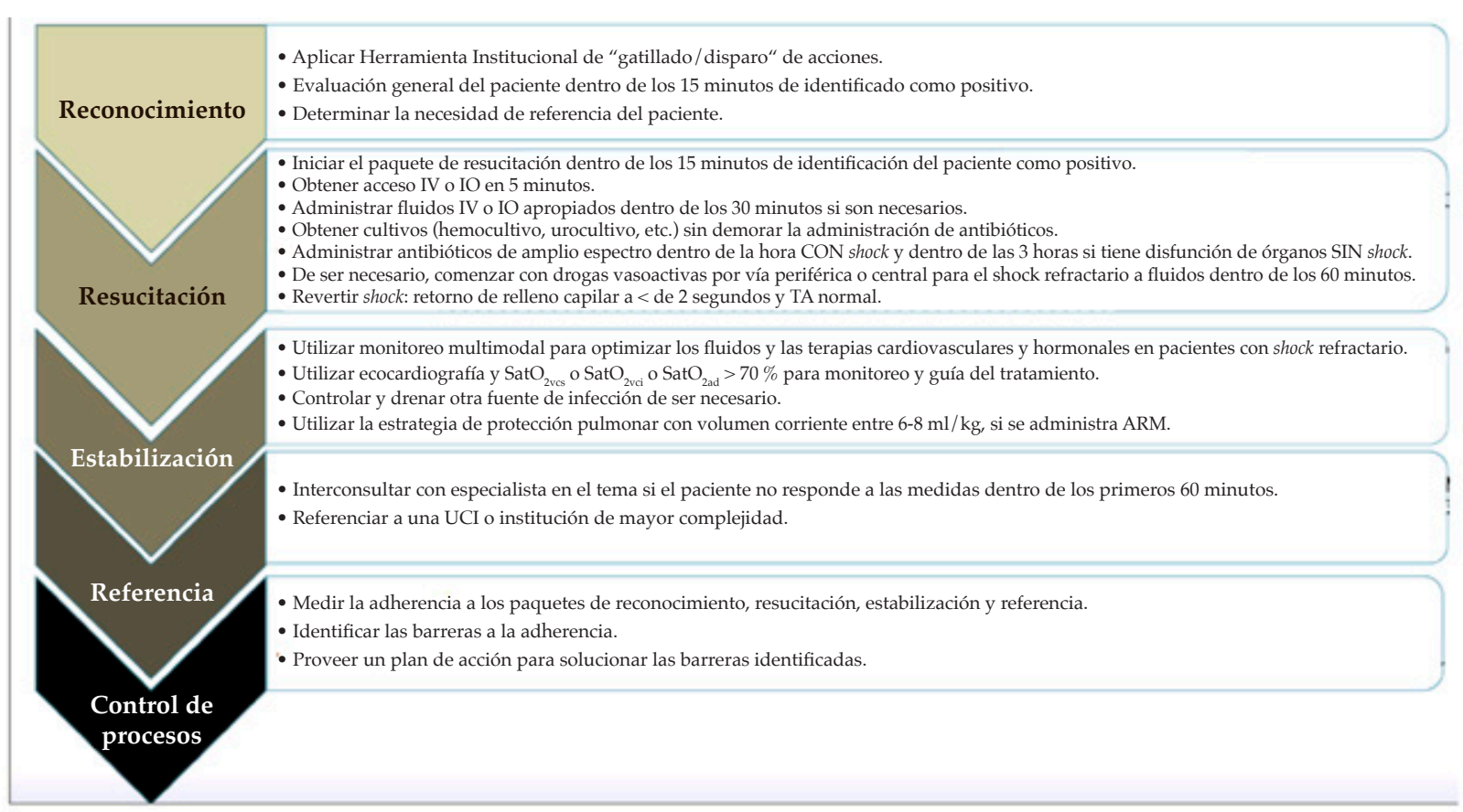

IV: intravenoso; IO: intraóseo; $\mathrm{TA}$ : tensión arterial; $\mathrm{SatO}_{2 \mathrm{vcs}}$ : saturación de oxígeno en vena cava superior; $\mathrm{SatO}_{2 \mathrm{vci}}$ : saturación de oxígeno en vena cava inferior; $\mathrm{SatO}_{2 \mathrm{ad}}$ : saturación de oxígeno en aurícula derecha; $\mathrm{ARM}$ : asistencia respiratoria mecánica. 
oportuna con intervención de profesionales idóneos ante una inadecuada respuesta al tratamiento y la medición de los procesos con correcciones de lo realizado. ${ }^{5,29,32,33}$ En el SIM-C, es pertinente la participación de pediatras especialistas en Emergencias, Cuidados Críticos, Medicina Interna, Infectología, Inmunología y Reumatología. 5,29

Se sugiere la aplicación de un protocolo de tratamiento guiado por metas (TGM) en el SIM-C por la evidencia de su aplicación en el ShS en pediatría, a pesar de las críticas en adultos. ${ }^{34-39}$ Pero su uso riguroso en todos los pacientes y en todas las instituciones por igual no siempre obtiene resultados similares, probablemente, por no involucrar a quienes toman las decisiones cerca del paciente. ${ }^{40-43}$ Así, es indispensable desarrollar una GPI acorde a los recursos disponibles en cada centro y la necesaria participación de todo el equipo sanitario. ${ }^{29}$

\section{PAQUETE DE RECONOCIMIENTO}

La detección precoz del SIM-C es fundamental para el tratamiento óptimo sensible al tiempo; por ello, es esencial visibilizar sus criterios clínicos. El SIM-C se caracteriza por una respuesta inflamatoria continua y progresiva. Ha recibido varios nombres, como síndrome inflamatorio multisistémico pediátrico temporalmente asociado a COVID-19 (paediatric inflammatory multisystem syndrome temporally associated with COVID-19; PIMS-TC, por sus siglas en inglés) y SIM-C, más estricto, específico y el adoptado en esta revisión. ${ }^{15,16,44} \mathrm{Al}$ igual que en otras entidades evolutivas, dinámicas y con límites imprecisos, la utilización de criterios clínicos rígidos podría entorpecer su reconocimiento inicial. ${ }^{45-47}$

La definición de la Organización Mundial de la Salud (OMS) incluye a niños de 0 a 19 años con fiebre persistente (> 3 días) asociada a manifestaciones clínicas en dos o más

TABLA 1. Edad, manifestaciones clínicas y evolución del síndrome inflamatorio multisistémico temporalmente relacionado con COVID-19 acorde a distintas publicaciones ${ }^{13-15,20,21}$

\begin{tabular}{|c|c|c|c|c|c|c|c|}
\hline & \multicolumn{6}{|c|}{ Publicaciones (países donde se incluyeron los pacientes) } \\
\hline & & $\begin{array}{c}\text { Belhadjer } \\
\text { y cols. } \\
\text { (Francia } \\
\text { y Suiza) } \\
n=35\end{array}$ & $\begin{array}{l}\text { Verdoni } \\
\text { y cols. } \\
\text { (Italia) }\end{array}$ & $\begin{array}{c}\text { González- } \\
\text { Dambrauskas } \\
\text { y cols. (Italia, } \\
\text { España, } \\
\text { Chile, } \\
\text { Colombia, } \\
\text { EE. UU.) } \\
\text { n=17 }\end{array}$ & $\begin{array}{l}\text { Duffort y cols. } \\
\text { (EE. UU. })^{\mathrm{b}} \\
\qquad \mathrm{n}=99\end{array}$ & $\begin{array}{c}\text { Feldstein y } \\
\text { cols. } \\
\text { (EE. UU.) } \\
\text { n }=186\end{array}$ & $\begin{array}{c}\text { Davies y } \\
\text { cols. } \\
\text { (Reino } \\
\text { Unido) } \\
\\
\mathrm{n}=78\end{array}$ \\
\hline \multirow{8}{*}{ 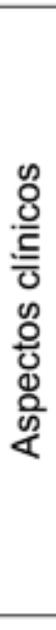 } & $\begin{array}{l}\text { Mediana de la } \\
\text { edad, en años }\end{array}$ & 10 & 7,5 & 4 & $\begin{array}{c}0-5 \text { años }=31 \text { pac. } \\
6-12 \text { años }=42 \text { pac. } \\
13-20 \text { años }= \\
26 \text { pac. }\end{array}$ & 8,3 & 11 \\
\hline & Fiebre (\%) & 100 & 100 & 76 & 100 & 100 & 100 \\
\hline & $\begin{array}{l}\text { Inyección } \\
\text { conjuntival (\%) }\end{array}$ & NR & 20 & NR & 56 & 55 & 29 \\
\hline & $\begin{array}{l}\text { Compromiso } \\
\text { cutáneo }(\%)\end{array}$ & 57 & 80 & 0 & 62 & 74 & 45 \\
\hline & $\begin{array}{l}\text { Compromiso } \\
\text { gastrointestinal } \\
(\%)\end{array}$ & 83 & 60 & 35 & 79 & 92 & 90 \\
\hline & $\begin{array}{l}\text { Compromiso } \\
\text { cardiaco }(\%)\end{array}$ & 80 & 60 & 24 & 53 & 80 & 87 \\
\hline & $\begin{array}{l}\text { Compromiso } \\
\text { respiratorio (\%) }\end{array}$ & 65 & NR & 35 & 40 & 70 & 85 \\
\hline & $\begin{array}{l}\text { Compromiso } \\
\text { neurológico (\%) }\end{array}$ & 31 & 40 & 17 & 30 & 6 & NR \\
\hline & Fallecidos (\%) & 0 & 0 & 6 & 2 & 2 & 2,6 \\
\hline
\end{tabular}

Pac. = se señala la cantidad de pacientes del grupo porque no se indica la mediana en el grupo.

NR: no hay referencia en el reporte.

El porcentaje (\%) señalado es la presentación de cada uno de los signos y síntomas en cada una de las series.

a Son datos de pacientes con COVID-19 en la UCIP, y es la única publicación hasta la actualidad con pacientes de Latinoamérica.

${ }^{\mathrm{b}}$ No informa mediana de edad, sino distribución por grupos etarios. 
FIGURA 2. Variables clínicas y de laboratorio en relación con la edad y con las presentaciones clínicas

\section{0-5 años}

\section{Alteraciones}

Mucocutáneas

100

Miocarditis

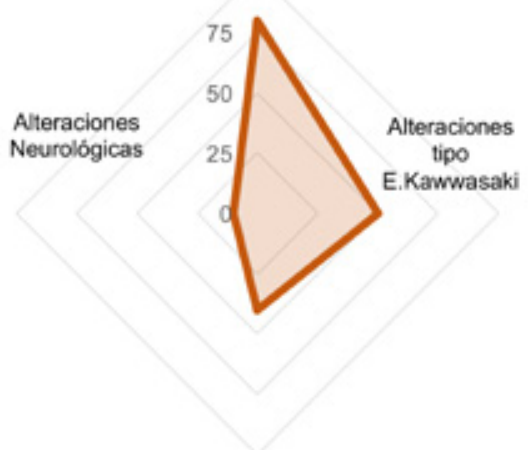

6-12 años

\section{Alteraciones}

Mucocutáneas

100

•SIM-C tipo E.Kawasaki

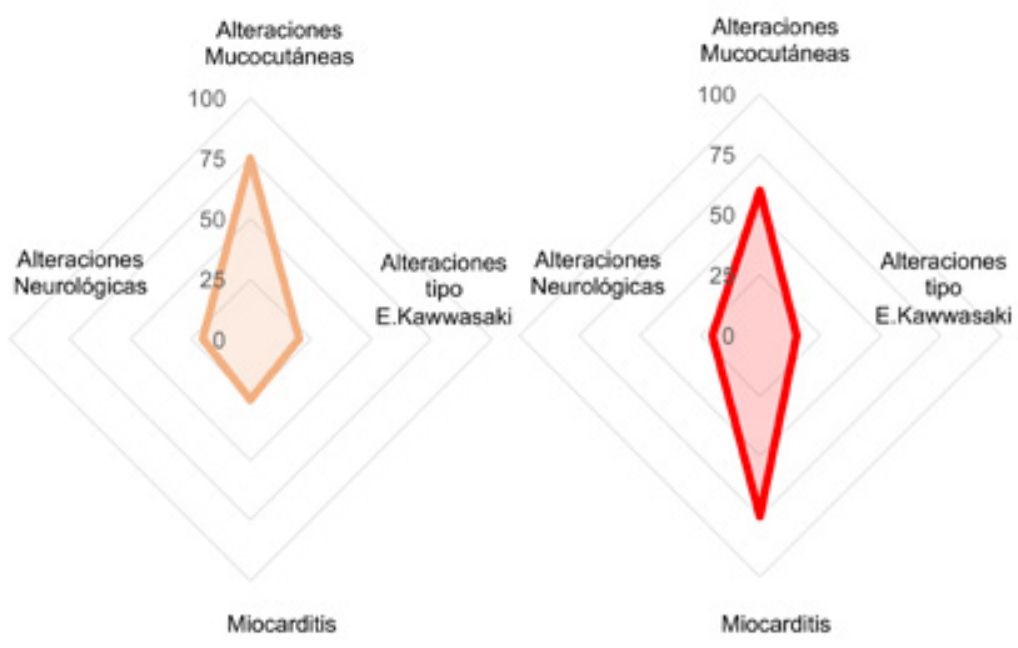

- SIM-C (propiamente dicho)
13-20 años

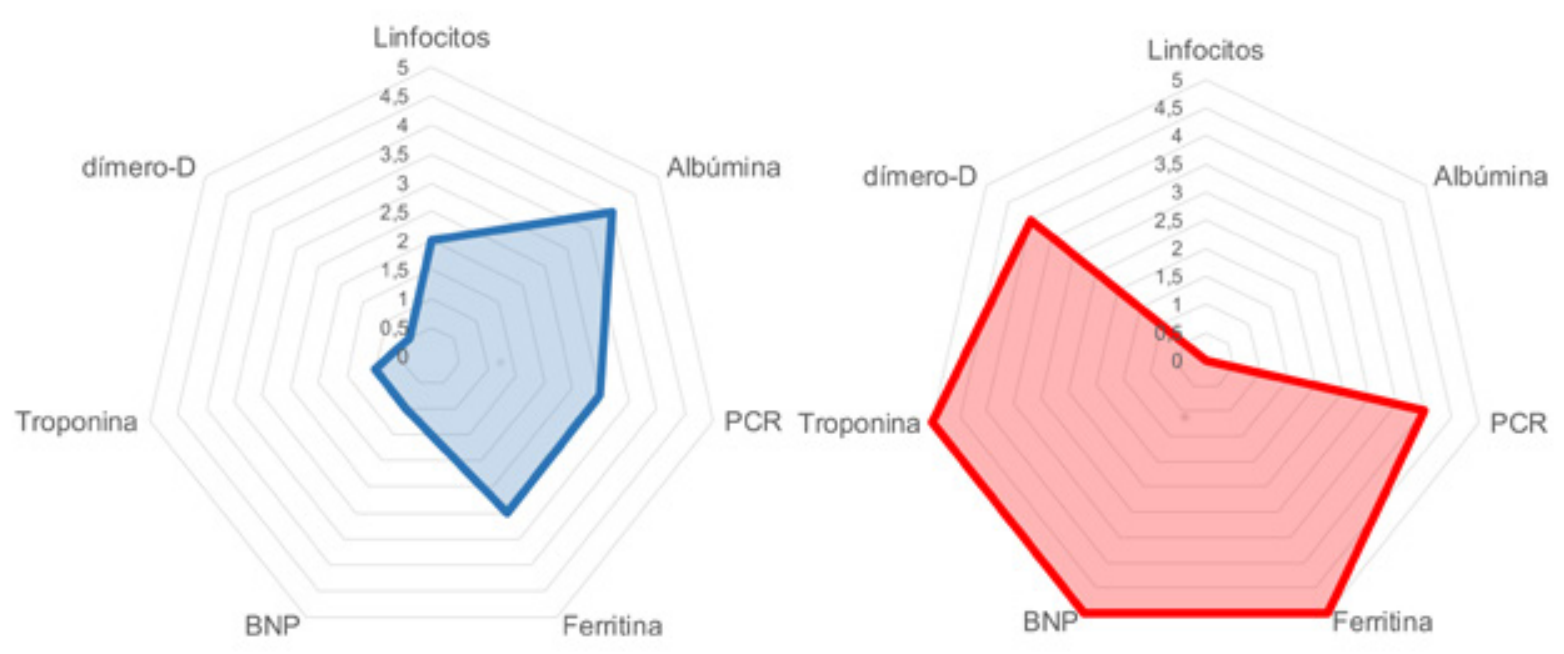

Gráfico de radar elaborado sobre la base de observaciones personales de Franco Díaz en Chile. En este, la magnitud de cada radio representa el valor de cada una de las variables.

A. Manifestaciones clínicas en pacientes entre 0 y 5 años. Se observa un predominio de las manifestaciones mucocutáneas y las variables de la enfermedad de Kawasaki o Kawasaki atípico.

B. Manifestaciones clínicas en pacientes de entre 6 y 12 años. Aún se observa predominio de manifestaciones cutáneas, aunque las manifestaciones neurológicas y las miocarditis comienzan a ser mayores que en A.

C. Manifestaciones clínicas en pacientes de entre 13 y 20 años. Predomina la miocarditis y las manifestaciones neurológicas, no así las mucocutáneas.

D. Variables bioquímicas en los pacientes con SARS-CoV-2 positivos y cuadro clínico parecido a enfermedad de Kawasaki, en una escala de 1 (menos probable de suceder) a 5 (más probable de suceder). Predomina el aumento de PCR y ferritina, con alteraciones en la albúmina y los linfocitos.

E. Variables bioquímicas en los pacientes con SARS-CoV-2 positivos y cuadro clínico de SIM-C, en una escala de 1 (menos probable de suceder) a 5 (más probable de suceder). Predomina el gran aumento de troponina, BNP, ferritina, PCR y dímero-D, y menos de linfocitos y alteraciones de albúmina.

EK: enfermedad de Kawasaki; EKa: enfermedad de Kawasaki atípica; SIM-C: síndrome inflamatorio sistémico asociado a COVID-19; PCR: proteína C reactiva. 
sistemas (mucocutáneo, circulatorio, cardíaco, hematológico y gastrointestinal); marcadores elevados de inflamación y ninguna otra causa microbiana obvia; con evidencia de COVID-19 (por reacción en cadena de polimerasa con transcriptasa reversa -reverse transcription polymerase chain reaction; $r t P C R$, por sus siglas en inglés-, prueba de antígeno o serología positiva) o

TABLA 2. Hallazgos de laboratorio acordes a distintas publicaciones ${ }^{13-15,20,21}$

\begin{tabular}{|c|c|c|c|c|c|c|c|}
\hline & \multicolumn{6}{|c|}{ Publicaciones (países donde se incluyeron los pacientes) } \\
\hline & & $\begin{array}{l}\text { Belhadjer y cols. } \\
\text { (Francia y Suiza) } \\
\qquad \mathrm{n}=35\end{array}$ & $\begin{array}{c}\begin{array}{c}\text { Verdoni y } \\
\text { cols. } \\
\text { (ltalla) }\end{array} \\
\mathrm{n}=10\end{array}$ & \begin{tabular}{|c|} 
González- \\
Dambrauskas \\
y cols. (Italia, \\
España, Chile, \\
Colombia, EE. UU.) \\
$n=17$
\end{tabular} & $\begin{array}{l}\text { Duffort y cols. } \\
\text { (EE. UU. })^{\mathrm{b}} \\
\qquad n=99\end{array}$ & $\begin{array}{l}\text { Feldstein y cols. } \\
\text { (EE. UU. })^{\circ} \\
n=186\end{array}$ & $\begin{array}{l}\text { Davies y cols. } \\
\text { (Reino Unido) } \\
\qquad n=78\end{array}$ \\
\hline \multirow{10}{*}{ 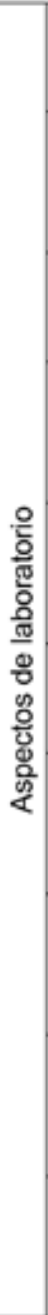 } & $\begin{array}{l}\text { Neutrófilos } \\
\text { Mayor valor } \times 10^{3} / \mathrm{ml} \text { (RIC) } \\
\%=\text { pacientes con } \\
\text { neutrofilia en la serie }\end{array}$ & $\begin{array}{c}13 \\
(8-19)\end{array}$ & $84,5 \%$ & NR & $0 \%$ & $68 \%$ & NR \\
\hline & $\begin{array}{l}\text { Linfocitos } \\
\text { Mayor valor } \times 10^{3} / \mathrm{ml}(\mathrm{RIC}) \\
{[\mathrm{DE}]} \\
\%=\text { pacientes con } \\
\text { linfopenia en la serie }\end{array}$ & NR & $\begin{array}{l}0 \cdot 86 \\
{[0,4]}\end{array}$ & $47 \%$ & $66 \%$ & $80 \%$ & $\begin{array}{c}0,80 \\
(0,41-1,1)\end{array}$ \\
\hline & $\begin{array}{l}\text { Plaquetas } \\
\text { Mayor valor } \times 10^{3} / \mathrm{ml}(\mathrm{RIC}) \\
\%=\text { pacientes con } \\
\text { plaquetopenia en la serie }\end{array}$ & NR & 130 & NR & $\begin{array}{c}155 \\
(105-233) \\
11 \%\end{array}$ & $\begin{array}{c}133 \\
(88-235) \\
55 \%\end{array}$ & $\begin{array}{c}151 \\
(93-208)\end{array}$ \\
\hline & $\begin{array}{l}\text { PCR } \\
\text { Mayor valor en mg/dl (RIC) } \\
\text { [DE] } \\
\% \text { = pacientes sobre el } \\
\text { punto de corte }\end{array}$ & $\begin{array}{c}24,1 \\
(15,0-31,1)\end{array}$ & $\begin{array}{c}25 \\
{[15,3]}\end{array}$ & $76 \%$ & $\begin{array}{c}21,9 \\
(15,0-30,0) \\
100 \%\end{array}$ & $\begin{array}{c}17,8 \\
(12,8-25,9) \\
91 \%\end{array}$ & $\begin{array}{c}25,1 \\
(19,2-30,7)\end{array}$ \\
\hline & $\begin{array}{l}\text { Ferritina } \\
\text { Mayor valor en ng/dl (RIC) } \\
\text { [DE] } \\
\% \text { = pacientes sobre el } \\
\text { punto de corte }\end{array}$ & NR & $\begin{array}{c}1176 \\
{[1032]}\end{array}$ & $41 \%$ & $\begin{array}{c}522 \\
(305-820) \\
75 \%\end{array}$ & $\begin{array}{c}639 \\
(332,7-1178,2) \\
61 \%\end{array}$ & $\begin{array}{c}958 \\
(516-1554)\end{array}$ \\
\hline & $\begin{array}{l}\text { Procalcitonina } \\
\text { Mayor valor en ng/dl (RIC) } \\
\%=\text { pacientes sobre el } \\
\text { punto de corte }\end{array}$ & $\begin{array}{c}36 \\
(8-99)\end{array}$ & NR & $35 \%$ & $\begin{array}{c}6,2 \\
(2,2-19,7) \\
92 \%\end{array}$ & NR & NR \\
\hline & $\begin{array}{l}\text { Troponina } \\
\text { Mayor valor en ng/l (RIC) } \\
\text { [DE] } \\
\%=\text { pacientes sobre el } \\
\text { punto de corte }\end{array}$ & $\begin{array}{c}347 \\
(186-1267)\end{array}$ & $\begin{array}{c}1004 \\
{[1862]}\end{array}$ & $25 \%$ & $71 \%$ & $50 \%$ & $\begin{array}{c}167 \\
(41-1112)\end{array}$ \\
\hline & $\begin{array}{l}\text { Pro-BNP } \\
\text { Mayor valor en pg/ml (RIC) } \\
\text { [DE] } \\
\%=\text { pacientes sobre el } \\
\text { punto de corte }\end{array}$ & $\begin{array}{c}5743 \\
(2648-11909)\end{array}$ & $\begin{array}{r}1255 \\
{[929]}\end{array}$ & NR & $90 \%$ & $\begin{array}{c}1194,7 \\
(390,8-4833) \\
73 \%\end{array}$ & NR \\
\hline & $\begin{array}{l}\text { Dimero-D } \\
\text { Mayor valor en ng/ml (RIC) } \\
\text { [DE] } \\
\% \text { = pacientes sobre el } \\
\text { punto de corte }\end{array}$ & $\begin{array}{c}5284 \\
(4069-9095)\end{array}$ & $\begin{array}{c}3798 \\
{[1318]}\end{array}$ & $41 \%$ & $\begin{array}{c}2400 \\
(1200-3700) \\
91 \%\end{array}$ & $\begin{array}{c}4090 \\
(2240-8404,5) \\
67 \%\end{array}$ & $\begin{array}{c}3750 \\
(2106-6958)\end{array}$ \\
\hline & $\begin{array}{l}\text { Fibrinógeno } \\
\text { Mayor valor en mg/dl (RIC) } \\
\text { [DE] } \\
\%=\text { pacientes sobre el } \\
\text { punto de corte }\end{array}$ & 0 & $\begin{array}{c}621 \\
{[182]}\end{array}$ & NR & $\begin{array}{c}624 \\
(506-764) \\
86 \%\end{array}$ & $80 \%$ & NR \\
\hline
\end{tabular}

RIC: rango intercuartilo; DE: desviación estándar; PCR: proteína C reactiva; pro-BNP: pro-péptido natriurético cerebral. Datos expresados según lo referido en las publicaciones: $\%(\mathrm{n} / \mathrm{N})$, acorde a los pacientes por encima del punto de corte. Puntos de corte:

a Puntos de corte: linfopenia < $1000\left(1 \times 10^{3}\right) / \mathrm{ml}$; PCR: > 0,2 mg/l; ferritina: > $200 \mathrm{ng} / \mathrm{ml}$; procalcitonina: $2 \mathrm{ng} / \mathrm{dl}$; dímero-D: > $500 \mathrm{ng} / \mathrm{ml}$; ferritina: $>300 \mathrm{ng} / \mathrm{ml}$.

${ }^{\mathrm{b}}$ Puntos de corte de estudio de Duffort: linfopenia $<2,5 \%$ ( $<1$ mes) $/<4,0 \%$ (1-12 meses) $/<3,0 \%(1-2$ años) $/<2,0 \%$ (2-4 años) $/<1,5 \%$ (4-10 años) $/<1,2 \%$ (10-16 años) $/<1,0 \%$ ( $>16$ años); plaquetopenia: $<80000$;

PCR (proteína C reactiva): $\geq 3 \mathrm{mg} / \mathrm{dl}$, ferritina: $>300 \mathrm{ng} / \mathrm{ml}$; procalcitonina: $0,5 \mathrm{ng} / \mathrm{dl}$; pro-BNP: $>1121 \mathrm{pg} / \mathrm{ml}$ (1 mes-1 año)/675 pg/ml (1-2 años)/391 pg/ml (2-14 años)/363 pg/ml (> 14 años); dímero-D: > 550 ng/ml; fibrinógeno: $>400 \mathrm{mg} / \mathrm{dl}$.

cPuntos de corte de estudio de Feldstein: plaquetopenia < 150000; PCR (proteína C reactiva): $\geq 3 \mathrm{mg} / \mathrm{dl}$; ferritina: $>500 \mathrm{ng} / \mathrm{ml}$; pro-BNP: > $400 \mathrm{pg} / \mathrm{ml}$; dímero-D: > $3000 \mathrm{ng} / \mathrm{ml}$; fibrinógeno: > $400 \mathrm{mg} / \mathrm{dl}$; NR: no hay referencia en el reporte. 
contacto con pacientes con COVID-19. En algunos casos, solo la sospecha clínica sería válida para asumir el cuadro como SIM-C. ${ }^{16}$

Publicaciones recientes describieron las características clínicas del SIM-C (se recomiendan sus lecturas para un informe más amplio) (Tabla 1).5,10-22 Se reportaron casos en todas las edades pediátricas y todas las etnias, a pesar de informes iniciales de mayor incidencia en afrodescendientes e hispanos. ${ }^{5,10-22}$ La mayoría señala un predominio entre los 6 y los 12 años, aunque el Critical Coronavirus and Kids Epidemiologic Study-CAKE- reportó una mediana de 4 años en los pacientes con COVID-19 internados en la Unidad de Cuidados Intensivos Pediátricos (UCIP). ${ }^{18}$ Los signos clínicos iniciales son fiebre alta y persistente $>3$ días, lesiones cutáneas maculopapulares similares a EK, síntomas digestivos (náuseas, vómitos, diarrea o dolor abdominal) y afectación miocárdica. ${ }^{5,10-22}$ Cuando el shock está presente, no se diferencia clínicamente del ShS. ${ }^{23-26,28,29} \mathrm{La}$ afectación cardíaca, presente en un alto porcentaje de pacientes, incluye la disfunción miocárdica, aneurismas de las arterias coronarias, pericarditis, arritmias, shock refractario y/o elevación de biomarcadores cardíacos, como la troponina I o del péptido natriurético cerebral, aun sin compromiso cardíaco importante. . $19,19,22,48-50^{-5}$

$C A K E$ reportó una menor frecuencia de compromiso cardíaco que otros estudios europeos ${ }^{18}$ que señalan, probablemente, fenotipos de la misma enfermedad. Duffort y cols.$^{19} \mathrm{y}$ Franco Díaz (comunicación personal sobre pacientes con SIM-C en Chile) señalaron que la presencia de signos clínicos y de laboratorio variaba con la edad. La afección cutánea y los signos semejantes predominarían en pacientes de 0 a 5 años, mientras que la miocarditis y los síntomas neurológicos, en aquellos de 13 a 20 años ${ }^{19}$ (Figura 2).

Los hallazgos más frecuentes en el laboratorio son leucocitosis, neutrofilia, linfopenia, anemia y trombocitopenia. ${ }^{2}$ Los biomarcadores inflamatorios se encuentran elevados (proteína $\mathrm{C}$ reactiva $-\mathrm{PCR}-$, procalcitonina, ferritina sérica, interleuquina 1 e interleuquina 6) (Tabla 2). Como en la sepsis, la elevación simultánea de PCR y ferritina se asocian a fenotipos de peores evoluciones. ${ }^{5,10-22,24-27,51}$

En el SIM-C, existe un estado procoagulante evidenciado por diferentes alteraciones bioquímicas. Si bien la coagulopatía inducida por el COVID-19 comparte características con otras, es probable que sea una nueva variedad..$^{52}$ A pesar del valor elevado de dímero-D, en el inicio, hay aumento del fibrinógeno, lo que señala una respuesta predominantemente inflamatoria (endotelitis) más que una coagulopatía de consumo. ${ }^{20,21,52}$ Como el ácido hialurónico sérico, componente clave del glucocálix, está más elevado durante la infancia, el endotelio podría estar más protegido, con menor probabilidad de un estado hipercoagulable..$^{53,54}$

Si hay una baja sospecha clínica de SIM-C, se propone solicitar el recuento de glóbulos blancos (RGB) con fórmula diferencial, además del recuento de plaquetas, PCR o la eritrosedimentación. Si la sospecha es fuerte o se confirma el SIM-C, sería pertinente solicitar estudios más extensos: ferritina, procalcitonina, troponina, dímero-D, estudios de coagulación, transaminasas y lactato deshidrogenasa. ${ }^{24-27}$

La aparición de casos de 4 a 6 semanas después de los picos regionales de la pandemia y de pacientes con rtPCR negativos con serología positiva (inmunoglobulina $\mathrm{G}-\mathrm{IgG}$ o inmunoglobulina $\mathrm{M}-\mathrm{IgM}$ - para severe acute respiratory syndrome coronavirus $2-S A R S-C o V-2-)$ respalda la hipótesis sobre un proceso inflamatorio posinfeccioso relacionado con COVID-19. ${ }^{10-22}$

Por lo inespecífico de los signos y síntomas y sus diferentes presentaciones, en contexto de pandemia y de acuerdo con la epidemiología local, en un paciente con un cuadro sospechoso, se debería pensar lo siguiente: “¿Podría ser SIM-C?". ${ }^{33}$ Se propone que aquellos con cuadros sugestivos, pero con estudios de laboratorio normales, reciban instrucciones específicas al egreso y sean controlados las siguientes 24-72 h en forma presencial o por telemedicina. ${ }^{25}$ Para el abordaje inicial del SIM-C, se ha modificado el esquema de los "seis pasos para la sepsis pediátrica", del Grupo de Sepsis Pediátrica del Reino Unido ${ }^{55}$ (Figura 3).

\section{PAQUETE DE REANIMACIÓN \\ Generalidades}

Como en el ShS, la reanimación está dirigida a corregir las alteraciones hemodinámicas y metabólicas. ${ }^{30,31,56}$ Previamente, se deben considerar los recursos locales, para que las recomendaciones no fracasen al sugerir elementos que no estuvieran disponibles (como pruebas de laboratorio, métodos de monitoreo u opciones de tratamiento) (Figura 4)..$^{57}$ 


\section{Monitoreo}

La carencia de monitoreo hemodinámico invasivo no justifica el retraso del tratamiento. El monitoreo no invasivo incluye el electrocardiograma continuo y la medición de la frecuencia respiratoria (FR), frecuencia cardíaca (FC), tensión arterial (TA), índice de shock (IS), saturación de oxígeno $\left(\mathrm{SatO}_{2}\right)$, flujo urinario (FU), temperatura rectal o axilar. ${ }^{30,31}$ De estar disponible, se aconseja utilizar variables

FIGURA 3. Seis pasos de la atención inicial del síndrome inflamatorio multisistémico temporalmente relacionado con COVID-19 (sepsis)

\section{Seis Pasos del SIM-C (Sepsis)}

\section{USE EQUIPO DE PROTECCIÓN PERSONAL}

- Niños/as y adolescentes de 0 a 19 años de edad con fiebre> 24 horas (puede incluir pacientes de hasta 21 años):

$\Rightarrow$ Si un nir̂o/a tiene al menos shock/choque o disfunción miocárdica MÁS

$\Rightarrow 2$ o más características clínicas * o epidemiológicas de SIM-C

$\Rightarrow$ o temperatura corporal $>38^{\circ} \mathrm{C}$ por $>24 \mathrm{hs}$, sin fuente definitiva

"Erupción cutánea o conjuntivitis no purulenta bilateral o signos de inflamación mucocutánea (oral, manos o pies), linfadenopatia,

caracteristicas de pericarditis, valvulitis o anomalias coronarias, coagulopatia, problemas gastrointestinales (diarrea, vómitos o

dolor abdominal), conocidos o sospecha de exposición a COVID o prueba positiva, marcadores elevados de inflamación (PCR, etc)

\section{Aplique un alto indice de sospecha en niños con enfermedades crónicas o inmunocomprometidos}

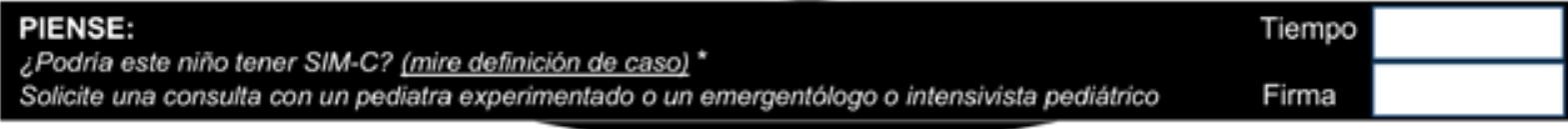

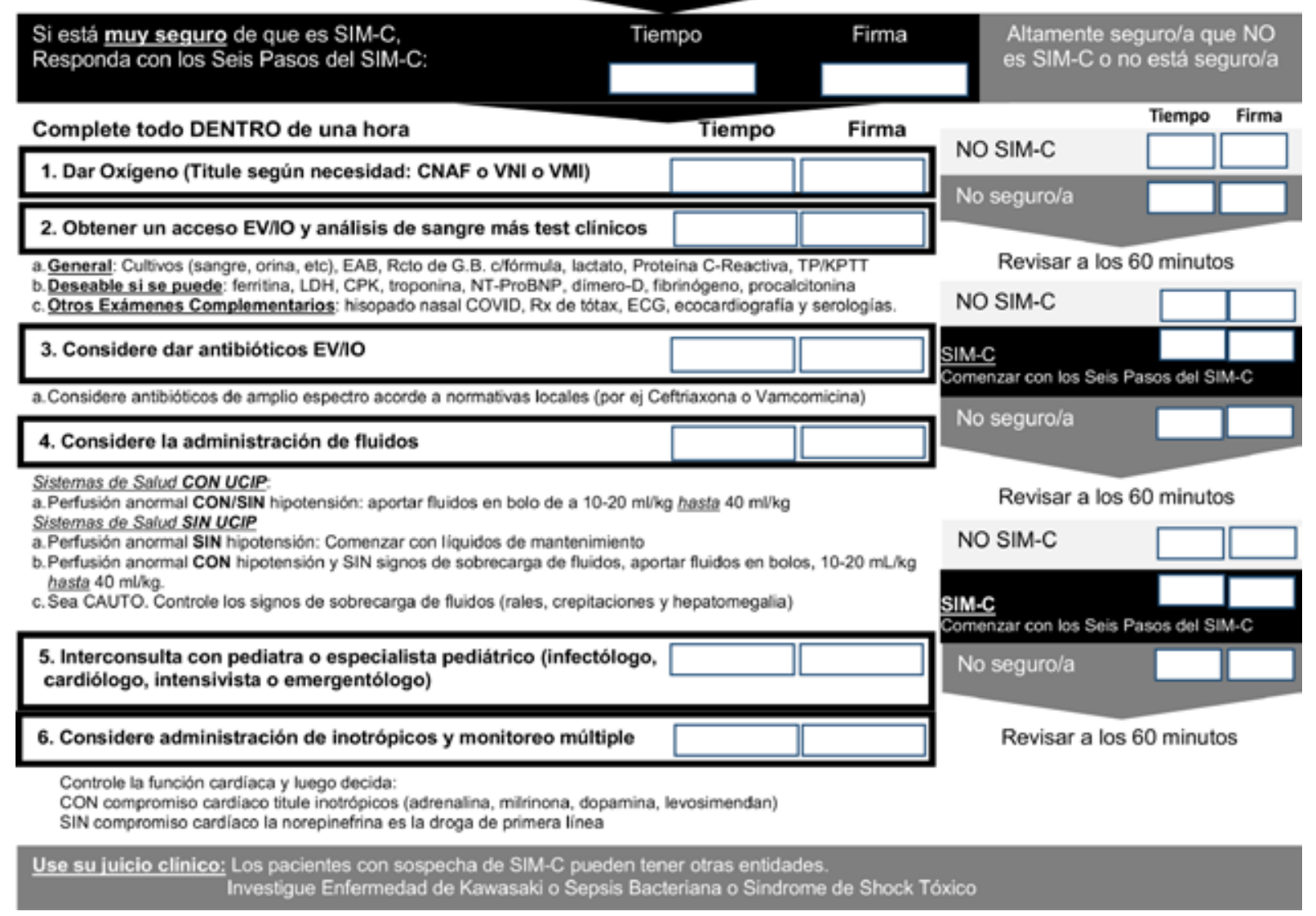

Traducido y modificado por los autores Tong J, Plunkett A, Daniels R. G218(P) The Paediatric sepsis 6 initiative. Arch Dis Child. 2014;99(S1):A93.

EV: endovenoso; IO: intraóseo; ECG: electrocardiograma. 
hemodinámicas avanzadas, además de las clínicas, para guiar la reanimación (TA invasiva continua, presión venosa central -PVC-y la $\mathrm{SatO}_{2}$ de la vena cava superior $-\mathrm{SatO}_{2 \mathrm{vcs}}-$ ). La meta de $\mathrm{SatO}_{2 \mathrm{vcs}}$ es $>70 \%$; el valor encontrado en la vena cava inferior $\left(\mathrm{SatO}_{2 \mathrm{vci}}\right)$ o en la aurícula derecha $\left(\mathrm{SatO}_{2 \mathrm{ad}}\right)$ también es válido. ${ }^{24-27,30,31,39,58,59}$ Aunque no hay evidencia para recomendar la medición de la presión de perfusión tisular/abdominal (PPT/ PPA), algunos expertos señalan como meta TA media (TAM) entre el percentil 5 y el 50 para la edad, y otros, una TAM mayor del percentil 50.24,27 Si las variables como estado mental, perfusión, diuresis y lactato mejoran, se podría tolerar una TA más baja. ${ }^{24,60}$ En el área de Emergencias, resulta práctico utilizar el IS (FC/TAS -TA sistólica-), disminuyendo la FC y subiendo la TAS. ${ }^{61,62}$

Amerita realizar una ecocardiografía para monitorear la función miocárdica por la posibilidad de disfunción cardíaca por hipertensión pulmonar (relacionada con el síndrome de dificultad respiratoria aguda -SDRA-, con la ventilación mecánica invasiva -VMI- o con tromboembolismo pulmonar), por miocarditis y la probabilidad de aneurismas de las coronarias (puntaje $\mathrm{Z}$ ajustado por superficie corporal > 2,5). . $^{50,63-65}$ Además, permite evaluar la hipovolemia al observar una vena cava inferior con variación mínima de su diámetro a lo largo del ciclo respiratorio. ${ }^{63}$ Esto posibilita revertir más rápidamente el shock, menor sobrecarga de fluidos, menor tiempo de internación y menor mortalidad en comparación con aquellos sin ecocardiografía. ${ }^{64}$ La SSC sugiere utilizar la tendencia de los niveles de lactato, más que su valor inicial, como complemento de la evaluación clínica. $^{24}$

\section{Metas}

Las metas no difieren de las señaladas en el ShS: obtener una vía aérea permeable con adecuada oxigenación y ventilación, normalizar la FC para la edad, los pulsos distales y centrales, el relleno capilar, la temperatura de la piel, el sensorio y optimizar el FU..$^{30}$ Alcanzar estas metas utilizando tratamientos escalonados redujo el $40 \%$ de la mortalidad por ShS pediátrico. ${ }^{37}$

FIGURA 4. Niveles de atención, recursos y manejo posible (modificado y traducido del original) ${ }^{55}$

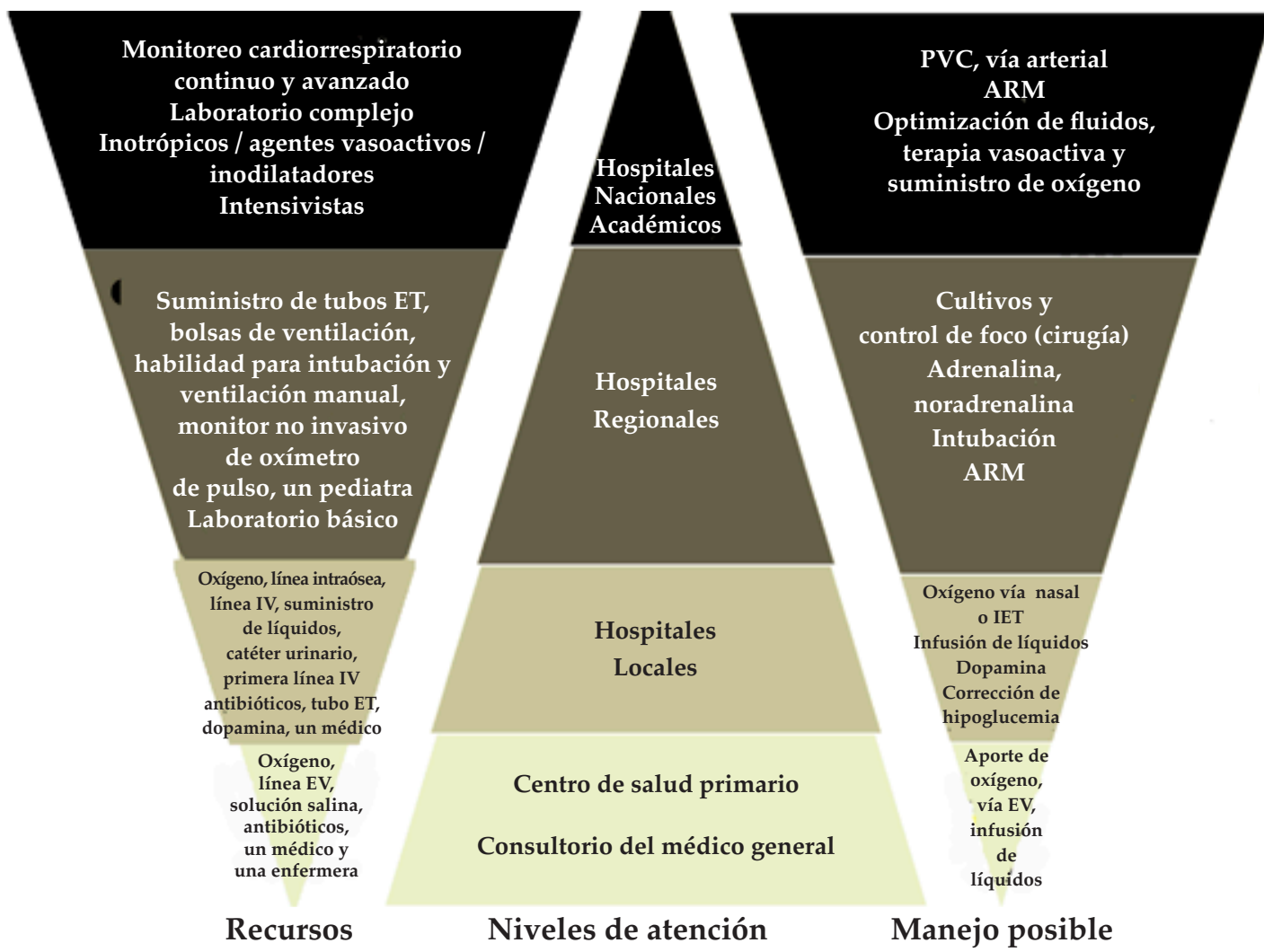

IV: intravenoso; IO: intraóseo; ET: endotraqueal; PVC: presión venosa central; ARM: asistencia respiratoria mecánica 


\section{Tratamiento}

a. Oxigenoterapia: La administración de oxígeno $\left(\mathrm{O}_{2}\right)$ suplementario debe ser acorde al nivel de requerimiento basado en la hipoxemia y el trabajo respiratorio. ${ }^{24-27}$ Por el riesgo del aerosol de partículas virales, se deben utilizar estrictamente las medidas de protección personal y, de disponerse, habitaciones de aislamiento. Se sugiere comenzar con una cánula nasal de bajo flujo cuando las saturaciones de oxígeno $\left(\mathrm{SpO}_{2}\right)$ sean $<90 \%$ y escalar, según las necesidades, a una cánula nasal de alto flujo (CNAF), luego a ventilación con presión positiva no invasiva (VPPNI), presión positiva continua en la vía aérea (continuous positive airway pressure; $C-P A P$, por sus siglas en inglés) o presión positiva de dos niveles (bilevel positive airway pressure; BiPAP, por sus siglas en inglés) y luego a VMI. ${ }^{27,66,67}$ Se debe evitar tanto la hipoxemia como la hiperoxia. ${ }^{68}$

b. Fluidos: Las recomendaciones sobre accesos vasculares son iguales a las del ShS. ${ }^{24-27,30,33}$ Los pacientes con SIM-C pueden presentar hipovolemia por las pérdidas gastrointestinales previas a la consulta, pero también, frecuentemente, tienen disfunción cardíaca. Se propone una estrategia de administración de fluidos "adecuada" a cada paciente y a los recursos disponibles: ${ }^{24,27}$

b.1. En los sistemas de atención médica con disponibilidad de UCIP (con personal y equipo para el manejo avanzado de las vías aéreas y administración de drogas vasoactivas), se deben administrar soluciones cristaloides balanceadas (Ringer lactato) hasta $40-60 \mathrm{ml} / \mathrm{kg}$ (10-20 ml/ $\mathrm{kg}$ por bolo) durante la primera hora, titularse según los marcadores clínicos de gasto cardíaco e interrumpirse si se desarrollan signos de sobrecarga de líquidos. ${ }^{24,27}$

b.2. Si no hay acceso a la UCIP y el paciente tiene hipotensión arterial, se deben administrar las soluciones cristaloides disponibles (balanceadas o no balanceadas) hasta $40 \mathrm{ml} /$ $\mathrm{kg}$ en bolo (10-20 ml $/ \mathrm{kg}$ por bolo) durante la primera hora, titularse según los marcadores clínicos de gasto cardíaco e interrumpirse al aparecer los signos de sobrecarga. . $^{2,27}$

b.3. Si no hay acceso a la UCIP y el paciente no tiene hipotensión arterial (shock compensado), se deben administrar fluidos de mantenimiento evitando el bolo, ya que empeora el resultado. ${ }^{24,27}$ Algunas GPC sugieren administrar los fluidos en 15 minutos, pero existe evidencia creciente sobre el riesgo de esta forma de administración y, en la práctica, es difícil de alcanzar. ${ }^{69,70}$ Por ello, un tiempo cercano a los 30 minutos podría ser una meta mas razonable. ${ }^{30}$

c. Drogas vasoactivas: Si no hay respuesta a los fluidos o ante la presencia de shock cardiogénico, debe iniciarse la infusión de drogas vasoactivas tanto por acceso venoso periférico (AVP) (en forma diluida), ${ }^{24}$ intraóseo o por un catéter venoso central (CVC). ${ }^{24-27,30}$ El patrón hemodinámico más frecuente en el SIM-C es el shock caliente; sin embargo, en algunos, predomina la disfunción contráctil. Por lo tanto, se propone el uso inicial de noradrenalina o adrenalina de acuerdo con el perfil hemodinámico del paciente. También se ha reportado el uso de dopamina, milrinona, levosimendán o vasopresina. ${ }^{10-22,24-27,30}$

d. Terapia con antibióticos: A pesar de ser una entidad viral, en la práctica, resulta muy difícil distinguir el SIM-C del ShS o el SST. Se sugiere utilizar, en el inicio, uno o más antibióticos empíricamente para cubrir todos los patógenos probables (sobre todo, estafilococo y estreptococo) y adecuarlos una vez identificado el gérmen. ${ }^{24}$ Estos deben ser administrados lo antes posible, idealmente, dentro de la primera hora. ${ }^{24,27}$ Es importante obtener antes hemocultivos, aunque no se debería retrasar la administración del antibiótico. ${ }^{24,27}$ Los focos infecciosos deberían ser controlados lo antes posible. ${ }^{24,27}$

e. Terapia antiviral: No hay evidencias suficientes para recomendar terapias farmacológicas para pacientes pediátricos con $S A R S-C o V-2$. Se propone decidir su uso junto con un equipo multiprofesional. ${ }^{71}$

\section{PAQUETE DE ESTABILIZACIÓN}

\section{(generalmente, luego de los 60 minutos)}

La inadecuada respuesta a las primeras medidas de reanimación requiere un monitoreo invasivo y tratamientos pertinentes a las UCIP que, si bien exceden los objetivos de este trabajo, merecen algunas consideraciones.

\section{Monitoreo}

Se debe completar el monitoreo inicial y, de disponerse, agregar la medición del gasto cardíaco. Se sugiere monitorear y tratar la aparición del síndrome compartimental, neumotórax y/o arritmias cardíacas por la 
probable miocarditis, así como mantener una glucemia $<180 \mathrm{mg} / \mathrm{dl}^{24}$

\section{Metas}

Continuar con las mismas metas y agregar la optimización de la VMI.

\section{Terapia inmunomoduladora}

Su indicación debe realizarse con un abordaje multidisciplinario por la escasa evidencia. ${ }^{25-27,71}$ En pacientes graves, podría administrarse antes de completar los estudios confirmatorios de SIM-C; no así en aquellos sin compromiso de vida. ${ }^{27,71}$

La dosis de inmunoglobulina endovenosa (IGEV) recomendada es de $1-2 \mathrm{~g} / \mathrm{kg}$ para los casos de moderados a graves (aquellos con compromiso miocárdico, shock persistente o altas dosis de vasopresores), y se necesitan, a veces, dos series de IGEV. 19,20,27,71 Puede considerarse el uso de metilprednisolona en dosis de bajas a moderadas en todos los casos de SIM-C; sin embargo, en presencia de shock o elevadas dosis de vasopresores, pueden indicarse altas dosis en pulso. ${ }^{27,71}$

En caso de ser refractario a la IGEV o a los corticoides, es necesario consultar con personal con experiencia en el uso de terapias biológicas antiinflamatorias, como anakinra y tocilizumab. ${ }^{72}$ Sin embargo, es excepcional su uso, al no estar definidas en pediatría sus indicaciones y los perfiles de seguridad.

\section{Aspectos hematológicos}

En pediatría, no se reportan las tasas de trombosis de los adultos y se recomienda documentar la trombosis además de un manejo multidisciplinario. ${ }^{10-22,73-76}$

a. Con riesgo leve de trombosis venosa (TV) (con CVC o periféricos permanentes o gravemente enfermos sin estado hiperinflamatorio y $\sin$ riesgo de trombosis), se debe considerar enoxaparina subcutánea para conseguir el nivel de factor anti- $X$ de $0,3-0,5 \mathrm{u} / \mathrm{ml}^{27}$

$<2$ meses: $0,75 \mathrm{mg} / \mathrm{kg} /$ dosis $\mathrm{c} / 12 \mathrm{~h}$

$>2$ meses: $0,5 \mathrm{mg} / \mathrm{kg} /$ dosis $\mathrm{c} / 12 \mathrm{~h}$

b. Con alto riesgo de TV (estado crítico, hiperinflamatorio-PCR $>150 \mathrm{mg} / \mathrm{l}$, dímero-D $>1500 \mathrm{ng} / \mathrm{ml}, \mathrm{IL}-6>100 \mathrm{pg} / \mathrm{ml}$, ferritina $>500 \mathrm{ng} / \mathrm{ml}-$, antecedentes de eventos tromboembólicos, fracción de eyección de ecocardiograma inferior al $35 \%$ ), se debe considerar enoxaparina subcutánea, para conseguir un nivel de factor anti-X de 0,5$1 \mathrm{u} / \mathrm{ml}:{ }^{27}$

$<2$ meses: $1,5 \mathrm{mg} / \mathrm{kg} /$ dosis c/ $12 \mathrm{~h}$
$>2$ meses: $1 \mathrm{mg} / \mathrm{kg} /$ dosis c/ $12 \mathrm{~h}$

En pacientes con trombocitosis $(>450000 \mathrm{u} / \mathrm{l})$ o criterios de EK "like", se sugiere administrar aspirina: $3-5 \mathrm{mg} / \mathrm{kg} /$ día (máximo de $81 \mathrm{mg} /$ día). ${ }^{72}$

Se desaconseja transfundir plaquetas si el paciente no presenta un sangrado activo, aun con anormalidades del recuento plaquetario. La transfusión de glóbulos rojos se indica con un nivel de hemoglobina $<7 \mathrm{~g} / \mathrm{dl}$ y si está hemodinámicamente estable. No hay una recomendación clara respecto al valor de hemoglobina en pacientes inestables. ${ }^{24}$

\section{PAQUETE DE REFERENCIA}

Los equipos especializados en pacientes críticos redujeron la mortalidad y mejoraron la evolución del ShS, lo que destacó la consulta a personal entrenado para un tratamiento adecuado y oportuno del SIM-C. ${ }^{77}$ Una nueva modalidad, la teleasistencia (consulta a distancia mediante medios informáticos: celulares, computadoras, etc.) permite la consulta de un experto en forma virtual y a distancia. ${ }^{78-83}$

\section{PAQUETE DE MEDICIÓN DE RESULTADOS}

La implementación de este paquete permite mejoras en los procesos de cuidado. ${ }^{41-43,84}$ Los puntos para medir sugeridos son adherencia a los paquetes de medidas, logro de metas establecidas, descripción de barreras, efectos indeseados hallados, adherencia para administrar los antibióticos a tiempo. ${ }^{30}$

\section{CONCLUSIÓN}

El SIM-C es una nueva forma del COVID-19 en niños y adolescentes de la cual aún resta mucho por estudiarse. Su baja prevalencia no anula la necesidad de conocer su diagnóstico y tratamiento, debido a que algunos pacientes con COVID-19 con escasos síntomas podrían deteriorarse rápidamente. Sus manifestaciones clínicas, laboratorio y curso natural cumplen con los criterios de sepsis de etiología viral con disfunción orgánica y, por lo tanto, su abordaje inicial debería ser muy similar.

\section{REFERENCIAS}

1. World Health Organization. Naming the coronavirus disease (COVID-19) and the virus that causes it. Geneva: WHO, Council for International Classification of Diseases (ICD). [Consulta: 10 de julio de 2020]. Disponible en: https: / / www.who.int / emergencies / diseases / novel-coronavirus-2019/technical-guidance/namingthe-coronavirus-disease-(covid-2019)-and-the-virus-thatcauses-it.

2. Hoang A, Chorath K, Moreira A, Evans M, et al. 
COVID-19 in 7780 pediatric patients: A systematic review. EClinicalMedicine. 2020. [Consulta: 10 de julio de 2020]. Disponible en: https: / / www.thelancet.com/ pdfs / journals / eclinm / PIIS2589-5370(20)30177-2.pdf.

3. Qiu H, Wu J, Hong L, Lou Y, et al. Clinical and epidemiological features of 36 children with coronavirus disease 2019 (COVID-19) in Zhejiang, China: an observational cohort study. Lancet Infect Dis. 2020;20(6):68996.

4. Chao JY, Derespina KR, Herold BC, Goldman D, et al. Clinical Characteristics and Outcomes of Hospitalized and Critically Ill Children and Adolescents with Coronavirus Disease 2019 (COVID-19) at a Tertiary Care Medical Center in New York City. J Pediatr. 2020;223:14-9.e2.

5. InternationalPediatric Association, UNICEF.Epidemiology, Spectrum, and Impact of COVID-19 on Children, Adolescents, and Pregnant Women. [Consulta: 10 de julio de 2020] Disponible en: https://ipa-world.org/societyresources/code/images/x5f7u8p3T41e.pdf.

6. Dong $\mathrm{YMoX}, \mathrm{Hu} Y, \mathrm{QiX}$, etal.Epidemiologicalcharacteristics of 2143 pediatric patients with 2019 coronavirus disease in China. Pediatrics. 2020, [Consulta: 10 de julio de 2020]. Disponible en: https:/ / pediatrics.aappublications.org/ content/ pediatrics / early / 2020/03/16/ peds.2020-0702. full.pdf.

7. Centers for Disease Control and Prevention -CDCCOVID-19 Response Team. Coronavirus Disease 2019 in Children - United States, Febrero 12-Abril 2, 2020. MMWR Morb Mortal Wkly Rep. 2020;69(14):422-6.

8. Lu X, Zhang L, Du H, Zhang J, et al. SARS-CoV-2 Infection in Children. N Engl J Med. 2020;382(17):1663-5.

9. Parri N, Lenge M, Buonsenso D. Coronavirus Infection in Pediatric Emergency Departments (CONFIDENCE) Research Group. Children with Covid-19 in Pediatric Emergency Departments in Italy. $N$ Engl J Med. 2020;383(2):187-90.

10. Riphagen S, Gomez X, Gonzalez-Martinez C, Wilkinson $\mathrm{N}$, et al. Hyperinflammatory shock in children during COVID-19 pandemic. Lancet. 2020;395(10237):1607-8.

11. European Centre for Disease Prevention and Control (ECDC). Paediatric inflammatory multisystem syndrome and SARS-CoV-2 infection in children. Mayo 152020. Estocolmo. 2020. [Consulta: 10 de julio de 2020]. Disponible en: https: / / www.ecdc.europa.eu/sites / default / files / documents / covid-19-risk-assessmentpaediatric-inflammatory-multisystem-syndrome-15May-2020.pdf.

12. Centers for Disease Control and Prevention. Information for Healthcare Providers about Multisystem Inflammatory Syndrome in Children (MIS-C). [Consulta: 10 de julio de 2020]. Disponible en: https: / / www.cdc.gov/mis-c/hcp / index.html.

13. Belhadjer Z, Méot M, Bajolle F, Khraiche D, et al. Acute heart failure in multisystem inflammatory syndrome in children (MIS-C) in the context of global SARS-CoV-2 pandemic. Circulation. 2020. [Consulta: 10 de julio de 2020]. Disponible en: https: / / www.ahajournals.org/doi / pdf/10.1161/CIRCULATIONAHA.120.048360.

14. Verdoni L, Mazza A, Gervasoni A, Martelli L, et al. An outbreak of severe Kawasaki-like disease at the Italian epicentre of the SARS-CoV-2 epidemic: an observational cohort study. Lancet. 2020;39 (10239):1771-8.

15. Centers for Disease Control and Prevention. Multisystem Inflammatory Syndrome in Children (MIS-C) associated with coronavirus disease 2019 (COVID-19). [Consulta: 10 de julio de 2020]. Disponible en: https:/ / emergency.cdc. gov/han/2020/han00432.asp.

16. World Health Organization. Multisystem inflammatory syndrome in children and adolescents with COVID 19 Scientific brief. Mayo 15 2020. [Consulta: 10 de julio de 2020]. Disponibleen:https: / / www.who.int/publicationsdetail/multisystem-inflammatory-syndrome-in-childrenand-adolescents-with-covid-19.

17. DeBiasi RL, Song X, Delaney M, Bell M, et al. Severe COVID-19in Children and Young Adults in the Washington, DC Metropolitan Region. J Pediatr. 2020;223:199-203.e1.

18. González-DambrauskasS, Vásquez-Hoyos P,Camporesi A, Díaz-Rubio F, et al. Pediatric Critical Care and COVID19. Pediatrics. 2020;e20201766.

19. Belot A, Antona D, Renolleau S, Javouhey E, et al. SARSCoV-2-related paediatric inflammatory multisystem syndrome, an epidemiological study, France, 1 march to 17 may 2020. Euro Surveill. 2020;25(22):2001010.

20. Dufort EM, Koumans EH, Chow EJ, Rosenthal E, et al. Multisystem Inflammatory Syndrome in Children in New York State. N Engl J Med. 2020;NEJMoa2021756.

21. Feldstein LR, Rose EB, Horwitz SM, Collins J, et al. Multisystem Inflammatory Syndrome in U.S. Children and Adolescents. N Engl J Med. 2020;NEJMoa2021680.

22. Davies P, Evans C, Kanthimathinathan HK, Lillie J, et al. Intensive care admissions of children with paediatric inflammatory multisystem syndrome temporally associated with SARS-CoV-2 (PIMS-TS) in the UK: a multicentreobservational study. Lancet Child Adolesc Health. 2020;S2352-4642(20)30215-7.

23. Singer M, Deutschman CS, Seymour CW, Shankar-Hari $\mathrm{M}$, et al. The Third International Consensus Definitions for Sepsis and Septic Shock (Sepsis-3). JAMA. 2016;315 (8):801-10.

24. Weiss SL, Peters MJ, Alhazzani W, Agus MS, et al. Surviving sepsis campaign international guidelines for the management of septic shock and sepsis-associated organ dysfunction in children. Intensive Care Med. 2020;46(Suppl 1):10-67.

25. Hennon TR, Penque MD, Abdul-Aziz R, Alibrahim OS, et al. COVID-19 associated Multisystem Inflammatory Syndrome in Children (MIS-C) guidelines; a Western New York approach. Progress Pediatr Cardiol. 2020. [Consulta: 10 de julio de 2020]. Disponible en: https: / / www.ncbi.nlm. nih.gov/pmc/articles/PMC7244417/pdf/main.pdf.

26. Nakra NA, Blumberg DA, Herrera-Guerra A, Lakshminrusimha S. Multi-System Inflammatory Syndrome in Children (MIS-C) Following SARS-CoV-2 Infection: Review of Clinical Presentation, Hypothetical Pathogenesis, and Proposed Management. Children (Basel). 2020;7(7):E69.

27. Kache S, Chisti MJ, Gumbo F, Mupere E, et al. COVID-19 PICU guidelines: for high- and limited-resource settings. Pediatr Res. 2020. [Consulta: 10 de julio de 2020] Disponible en: https: / / www.nature.com/articles / s41390-020-10539_reference.pdf.

28. Ministerio de Salud de Argentina. Definición de caso COVID-19. Consulta: 10 de julio de 2020]. Disponible en: https: / / www.argentina.gob.ar/salud/ coronavirusCOVID-19/definicion-de-caso.

29. Kohn Loncarica G, Fustiñana A, Jabornisky R. Recomendaciones para el manejo del shock séptico en niños durante la primera hora (primera parte). Arch Argent Pediatr. 2019;117(1):e14-23.

30. Kohn Loncarica G, Fustiñana A, Jabornisky R. Recomendaciones para el manejo del shock séptico en niños durante la primera hora (segunda parte). Arch Argent Pediatr. 2019;117(1):e24-33.

31. Davis AL, Carcillo JA, Aneja RK, Deymann AJ, et al. American College of Critical Care Medicine Clinical Practice Parameters for Hemodynamic Support of Pediatric and 
Neonatal Septic Shock. Crit Care Med. 2017;45(6):1061-93.

32. Wip C, Napolitano L. Bundles to prevent ventilatorassociated pneumonia: how valuable are they? Curr Opin Infect Dis. 2009;22(2):159-66.

33. National Institute for Health and Care Excellence. Sepsis: Recognition, Assessment and Early Management. 2016. [Consulta: 10 de julio de 2020]. Disponible en: https: / / www.nice.org.uk/guidance/ng51/resources / sepsis-recognition-diagnosisand-early-managementpdf-1837508256709.

34. Peake SL, Delaney A, Bailey M, Bellomo R, et al. Goaldirected resuscitation for patients with early septic shock. N Engl J Med. 2014;371(16):1496-506.

35. Yealy DM, Kellum JA, Huang DT, Barnato A, et al. A randomized trial of protocol-based care for early septic shock. N Engl J Med. 2014;370(18):1683-93.

36. Mouncey PR, Osborn TM, Power GS, Harrison DA, et al. Trial of early, goal directed resuscitation for septic shock. N Engl J Med 2015;372(14):1301-11.

37. Han YY, Carcillo JA, Dragotta MA, Bills DM, et al. Early reversal of pediatric-neonatal septic shock by community physicians is associated with improved outcome. Pediatrics. 2003;112(4):793-9.

38. Ventura AM, Shieh HH, Bousso A, Góes P, et al. Doubleblind prospective randomized controlled trial of dopamine versus epinephrine as first-line vasoactive drugs in pediatric septic shock. Crit Care Med. 2015;43(11):2292-302.

39. De Oliveira CF, De Oliveira DS, Gottschald AF, Moura J, et al. ACCM/PALS haemodynamic support guidelines for paediatric septic shock: An outcomes comparison with and without monitoring central venous oxygen saturation. Intensive Care Med. 2008;34(6):1065-75.

40. Balamuth F, Weiss SL, Fitzgerald JC, Hayes K, et al. Protocolized Treatment Is Associated With Decreased Organ Dysfunction in Pediatric Severe Sepsis. Pediatr Crit Care Med. 2016;17(9):817-22.

41. Cruz AT, Perry AM, Williams EA, Graf J, et al. Implementation of goal-directed therapy for children with suspected sepsis in the emergency department. Pediatrics. 2011;127(3):e758-66.

42. Larsen GY, Mecham N, Greenberg R. An emergency department septic shock protocol and care guideline for children initiated at triage. Pediatrics 2011;127(6):e1585-92.

43. Paul R, Neuman M, Monuteaux MC, Melendez E. Adherence to PALS Sepsis Guidelines and Hospital Length of Stay. Pediatrics 2012;130(2):e273-80.

44. Royal College of Paediatrics and Child Health. Guidance: paediatric multisystem inflammatory syndrome temporally associated with COVID-19 (PIMS). 2020 [Consulta: 10 de julio de 2020]. Disponible en: https://www.rcpch. ac.uk/ sites / default / files / 2020-05/COVID-19-Paediatricmultisystem-\%20inflammatory\%20syndrome-20200501. pdf.

45. Angus D, Seymour C, Coopersmith CM, Deutschman C, et al. Framework for the Development and Interpretation of Different Sepsis Definitions and Clinical Criteria. Crit Care Med. 2016;44(3):e113-21.

46. Vincent JL, Opal SM, Marshall JC, Tracey K. Sepsis definitions: time for change. Lancet. 2013;381(9868):774-5.

47. Seymour CW, Liu VX, Iwashyna TJ, Brunkhorst F, et al. Assessment of Clinical Criteria for Sepsis: For the Third International Consensus Definitions for Sepsis and Septic Shock (Sepsis-3). JAMA. 2016;315(8):762-74.

48. Tan W, Aboulhosn J. The cardiovascular burden of coronavirus disease 2019 (COVID-19) with a focus on congenital heart disease. Int J Cardiol. 2020;309:70-7.

49. Tunuguntla H, Jeewa A, Denfield SW. Acute Myocarditis and Pericarditis in Children. Pediatr Rev. 2019;40(1):14-25.
50. Ramcharan T, Nolan O, Lai CY, Prabhu N, et al. Paediatric Inflammatory Multisystem Syndrome: Temporally Associated withSARS-CoV-2 (PIMS-TS): CardiacFeatures, Management and Short-Term Outcomes at a UK Tertiary Paediatric Hospital. Pediatr Cardiol. 2020;1-11.

51. Horvat C, Bell J,Kantawala S, Ku A, et al. C-Reactive protein and Ferritin Are Associated with Organ Dysfunction and Mortality in Hospitalized Children. Clin Pediatr (Phila). 2019:58 (7):752-60.

52. Iba T, Levy JH, Connors JM, Warketin T, et al. The unique characteristics of COVID-19 coagulopathy. Crit Care. 2020;24(1):360.

53. Trivedi P, Cheeseman P, Mowat AP. Serum hyaluronic acid in healthy infants and children and its value as a marker of progressive hepatobiliary disease starting in infancy. Clin Chim Acta. 1993;215(1):29-39.

54. Fernández-Sarmiento J, Salazar-Peláez LM, Carcillo JA. The Endothelial Glycocalyx: A Fundamental Determinant of Vascular Permeability in Sepsis. Pediatr Crit Care Med. 2020;21(5):e291-300.

55. Tong J, Plunkett A, Daniels R. G218(P) The Paediatrict sepsis 6 initiative. Arch Dis Child. 2014;99(Suppl 1):A93.

56. Jabornisky R, Mansur A. Shock. En Sociedad Argentina de Pediatría. PRONAP 2013;1:81-109.

57. Kissoon N. Sepsis guideline implementation: benefits, pitfalls and possible solutions. Crit Care. 2014;18(2):207.

58. CarcilloJA, Han K, Lin J, Orr R. Goal-Directed Management of Pediatric Shock in the Emergency Department. Clin Pediatr Emerg Med. 2007;8(3):165-75.

59. Han YY, Carcillo JA, Espinosa V, Kissoon N, et al. Quality improvement analysis of the global pediatric sepsis initiative registry. Pediatr Crit Care Med. 2014;15(4 Suppl):15-6.

60. Haque IU, Zaritsky AL. Analysis of the evidence for the lower limit of systolic and mean arterial pressure in children. Pediatr Crit Care Med. 2007;8(2):138-44.

61. Yasaka Y, Khemani RG, Markovitz BP. Is Shock index associated with outcome in children with sepsis/septic shock? Pediatr Crit Care Med. 2013;14(8):e372-9.

62. Berger T, Green J, Horeczko T, Hagar Y, etal.Shock index and early recognition of sepsis in the emergency department: pilot study. West J Emerg Med. 2013;14(2):168-74.

63. Arya B, Kerstein D, Leu CS, Hayes D, et al. Echocardiographic assessment of right atrial pressure in a pediatric and young adult population. Pediatr Cardiol. 2016;37(3):558-67.

64. El-Nawawy AA, Abdelmohsen AM, Hassouna HM. Role of echocardiography in reducing shock reversal time in pediatric septic shock: a randomized controlled trial. J Pediatr (Rio J). 2018;94(1):31-9.

65. Sociedad Argentina de Pediatría; Sociedad Argentina de Cardiología. Enfermedad de Kawasaki: Consenso interdisciplinario e intersociedades (guía práctica clínica). Versión abreviada. Arch Argent Pediatr. 2016;114(4):385-90.

66. World Health Organization. Oxygen therapy for children: a manual for health workers. Ginebra: WHO;2016. [Consulta: 10 de julio de 2020]. Disponible en: http:/ / www.who.int / maternal_child_adolescent/documents / child-oxygentherapy/en/.

67. World Health Organization. Clinical management of severe acute respiratory infection when novel coronavirus (2019-nCoV) infection is suspected. 2020. [Consulta: 10 de julio de 2020]. Disponible en: https:/ / apps.who.int/iris / handle/10665/330893.

68. Cam BV, Tuan DT, Fonsmark L, Poulsen A, et al. Randomized comparison of oxygen mask treatment vs nasal continuous positive airway pressure in dengue shock syndrome with acute respiratory failure. J Trop Pediatr. 2002;48(6):335-9. 
69. Kohn-Loncarica GA, Fustiñana AL, Jabornisky RM, Pavlicich S, et al. How Are Clinicians Treating Children With Sepsis in Emergency Departments in Latin America?: An International Multicenter Survey. Pediatr Emerg Care. 2019. [Consulta: 10 dejulio de 2020]. Disponibleen: https: / / journals.lww.com/pec-online/Abstract/9000/How_Are Clinicians_Treating_Children_With_Sepsis.98136.aspx.

70. Sankar J, Ismail J, Sankar MJ, Suresh CP, et al. Fluid Bolus Over 15-20 Versus 5-10 Minutes Each in the First Hour of Resuscitation in Children With SepticShock: A Randomized Controlled Trial. Pediatr Crit Care Med. 2017;18(10):e435-45.

71. Calvo C, García López-Hortelano M, De Carlos Vicente JC, Vázquez Martínez JL, et al. Recomendaciones sobre el manejo clínico de la infección por el «nuevo coronavirus» SARS-CoV2. An Pediatr (Barc). 2020;92(4):241.e1-11.

72. American College of Rheumatology. Clinical Guidance for Pediatric Patients with multisystem inflammatory syndrome in children (MIS-C) associated with SARS-CoV-2 and hyperinflammation in covid-19.2020. [Consulta: 10 de julio de 2020]. Disponibleen: https: / / www.rheumatology. org/Portals / 0 Files / ACR-COVID-19-Clinical-GuidanceSummary-MIS-C-Hyperinflammation.pdf.

73. Xie Y, Wang X, Yang P, Zhang S. COVID-19 Complicated by Acute Pulmonary Embolism. Radiology Cardiothoracic Imaging. 2020;2(2):e200067.

74. Tang N, Li D, Wang X, Sun Z. Abnormal coagulation parameters are associated with poor prognosis in patients with novel coronavirus pneumonia. J Thromb Haemost. 2020;18(4):844-7.

75. Li T, Lu H, Zhang W. Clinical observation and management of COVID-19 patients. Emerg Microbes Infect. 2020;9(1):68790.
76. Klok FA, Kruip MJHA, Van der Meer NJM, Arbous MS, et al. Incidence of thrombotic complications in critically ill ICU patients with COVID-19. Thromb Res. 2020;191:145-7.

77. Ninis N, Phillips C, Bailey L, Pollock JI, et al. The role of healthcare delivery in the outcome of meningococcal disease in children: case-control study of fatal and non-fatal cases. BMJ. 2005;330(7506):1475.

78. Rosenthal JL, Kissee JL, Marcin JP. To See or Not to See: Telemedicine's Impact on Triage Outcomes. Pediatr Critl Care Med. 2017;18(11):1081-3.

79. Harvey JB, Yeager BE, Cramer C, Wheeler D, et al. The Impact of Telemedicine on Pediatric Critical Care Triage. Pediatr Crit Care Med. 2017;18(11):e555-60.

80. Dharmar M, Romano PS, Kuppermann N, Nesbitt T, et al. Impact of critical care telemedicine consultations on children in rural emergency departments. Crit Care Med. 2013;41(10):2388-95.

81. GattuR,TeshomeG,LichensteinR.Telemedicineapplications for the pediatric emergency medicine: A review of the current literature. Pediatr Emerg Care. 2016;32(2):123-30.

82. Pannu J, Sanghavi D, Sheley T, Schroeder D, et al. Impact of telemedicine monitoring of community ICUs on interhospital transfers. Crit Care Med. 2017;45(8):1344-51.

83. Pujales G. Organización de un sistema de transporte de pacientes críticos. Mesa Redonda: Abordaje del niño y sus familias en situación de desastres. $8 .^{\circ}$ Congreso Argentino deEmergencias y Cuidados Críticos en Pediatría. 26-28 abril de 2017. Buenos Aires: Sociedad Argentina de Pediatría; 2017.

84. Fernández-Sarmiento J, Carcillo JA, Salinas CM, Galvis E, et al. Effect of a sepsis educational intervention on hospital stay. Pediatr Crit Care Med. 2018;19(6):e321-8. 